Indonesian Journal of Electronics and Instrumentation Systems (IJEIS)

Vol.9, No.2, October 2019, pp. 131 140

ISSN (print): 2088-3714, ISSN (online): 2460-7681

DOI: https://doi.org/10.22146/ijeis.47609

\title{
Model Identifikasi Kata Ucapan Tuna Wicara
}

\author{
Nuruddin Wiranda*1, Agfianto Eko Putra ${ }^{2}$ \\ ${ }^{1}$ Program Studi Pendidikan Ilmu Komputer, FKIP, ULM, Banjarmasin, Indonesia \\ ${ }^{2}$ Departemen Ilmu Komputer dan Elektronika, FMIPA, UGM, Yogyakarta, Indonesia \\ e-mail: *11nuruddin.wd@ulm.ac.id, ${ }^{2}$ agfi@ugm.ac.id
}

\begin{abstract}
Abstrak
Tuna wicara adalah ketidak-mampuan seseorang berbicara, padahal kemampuan berbicara merupakan hal penting agar dapat berkomunikasi dengan orang lain. Menyiasati hal tersebut seseroang yang mengalami tuna wicara memiliki cara tersendiri dalam berkomunikasi, yaitu dengan menggunakan bahasa isyarat, akan tetapi tidak semua orang memahami bahasa isyarat tersebut. Metode MFCC dan JST Backpropagation diimplementasikan pada Single Board Computer (SBC) dirancang untuk mengatasi permasalahan komunikasi tuna wicara. Metode MFCC digunakan untuk mengambil fitur dari suara tuna wicara dan JST Backpropagation digunakan untuk pengenalan pola suara.

Sistem dilatih menggunakan 750 sampel suara yang terdiri dari 5 penutur, masingmasing mengucapkan sebanyak 30 kali pengulangan pengucapan kata (makan, kamar, kerja, harga dan lapar), kemudian diuji menggunakan 125 sampel suara yang terdiri dari 5 penutur, masing-masing mengucapkan 5 kali pengulangan kata. Pelatihan dan pengujian JST Backpropagation menggunakan masukan koefisien yang dihasilkan dari MFCC. Hasil penelitian menunjukan bahwa Metode MFCC dan JST Backpropagation mampu mengidentifikasi ucapan kata tuna wicara dengan akurasi $60 \%$, presisi $40 \%$ dan sensitivitas $40 \%$.
\end{abstract}

Kata kunci-MFCC, JST Backpropagation, Single board computer, Tuna Wicara

\begin{abstract}
Speech impaired is the inability of someone to speak, even though speaking ability is important in order to communicate with other people. Dealing with this as someone who has speech impairments has their own way of communicating, namely by using sign language, but not everyone understands the sign language. The MFCC and Backpropagation ANN methods are implemented on a Single Board Computer (SBC) designed to overcome speech impaired communication problems. The MFCC method is used to retrieve the features of speech impairment and the Backpropagation ANN is used for sound pattern recognition.

The system was trained using 750 sound samples consisting of 5 speakers, each uttering as many as 30 repetitions of the pronunciation of words (makan, kamar, kerja, harga and lapar), then tested using 125 sound samples consisting of 5 speakers, each saying 5 repetitions of words. Training and testing of Backpropagation ANN using input coefficients generated from MFCC. The results showed that the MFCC and Backpropagation ANN methods were able to identify speech words with $60 \%$ accuracy, $40 \%$ precision and $40 \%$ sensitivity.
\end{abstract}

Keywords-MFCC, JST Backpropagation, Single board computer, Speech impaired

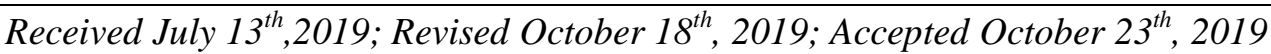




\section{PENDAHULUAN}

Tunawicara merupakan ketidak-mampuan seseorang dalam berbicara. Hal ini disebabkan oleh kurang atau tidak berfungsinya organ-organ untuk berbicara, seperti rongga mulut, langit langit, lidah dan pita suara. Selain itu juga adanya kekurangan pada indra pendengaran, keterlambatan perkembangan bahasa, kerusakan pada sistem syaraf dan struktur otot. Badan Pusat Statistik (BPS) menyajikan data statistik disabilitas dalam SUSENAS 2009 untuk penyandang tuna wicara berjumlah 151.427 dan tuna rungu wicara 73.587 jiwa di Indonesia[1].

Penelitian ini merancang-bangun sebuah sistem untuk membantu orang awam agar bisa mengerti apa yang diucapkan oleh tuna wicara menggunakan metode Mel Frequency Cepstral Coefficient (MFCC) dan Jaringan Saraf Tiruan (JST). Sistem ini memanfaatkan suara yang diucapkan oleh tunawicara tersebut, kemudian dilakukan proses pengenalan suara untuk mengetahui arti dari suara tersebut.

Beberapa penelitian dalam [2], [3], [4] dan [5] menyatakan bahwa ektraksi fitur menggunakan MFCC lebih unggul daripada menggunakan metode linear lain seperti LPCC dan LPC. Penelitian [6] melakukan penelitian menggunakan JST Backpropagation untuk melatih fitur yang di dapat dari MFCC dengan hasil akurasi mencapai 99.8\%. Sedangkan [7] dalam penelitiannya menggunakan ekstraksi fitur MFCC dan klasifikasi JST untuk mengidentifikasi Qori Qur'an memperoleh akurasi sebesar 91.2\%. Penelitian [8] menyimpulkan bahwa JST merupakan metode yang baik untuk pengenalan ucapan, sedangkan [9] dan [10] menggunakan JST dan MFCC untuk pengenalan suara dengan hasil akurasi sangat baik.

Tujuan dari penelitian yang dilakukan adalah merancang-bangun sistem yang mampu mengidentifikasi kata ucapan seorang tunawicara menggunakan metode MFCC dan JST Backpropagation. Hasil penelitian ini diharapkan dapat memberikan manfaat bagi orang awam agar bisa mengerti kata yang diucapkan oleh tunawicara.

\section{METODE PENELITIAN}

\subsection{Gambaran Keseluruhan Sistem}

Masukan sistem alat bantu tunawicara adalah suara yang ditangkap dari mikrofon dan 3 tombol yang berfungsi untuk mematikan, mereset sistem dan untuk merekam suara. Masukan dari mikrofon atau tombol diproses oleh aplikasi yang telah ditanamkan pada SBC, hasilnya ditampilkan pada LCD 2 x 16, sebagaimana diagram blok-nya ditunjukan pada Gambar 1.

Terdapat 2 tahapan proses utama dalam sistem identifikasi kata ucapan kata tunawicara yang dirancang-bangun, yaitu tahap pelatihan dan pengujian. Tahap pelatihan merupakan proses untuk melatih atau membimbing sistem agar dapat mengenali pola dari kata ucapan tunawicara. Sedangkan tahap pengujian merupakan proses untuk mengetahui kemampuan sistem dalam pengenalan pola berdasarkan tahapan pelatihan yang telah dilakukan.

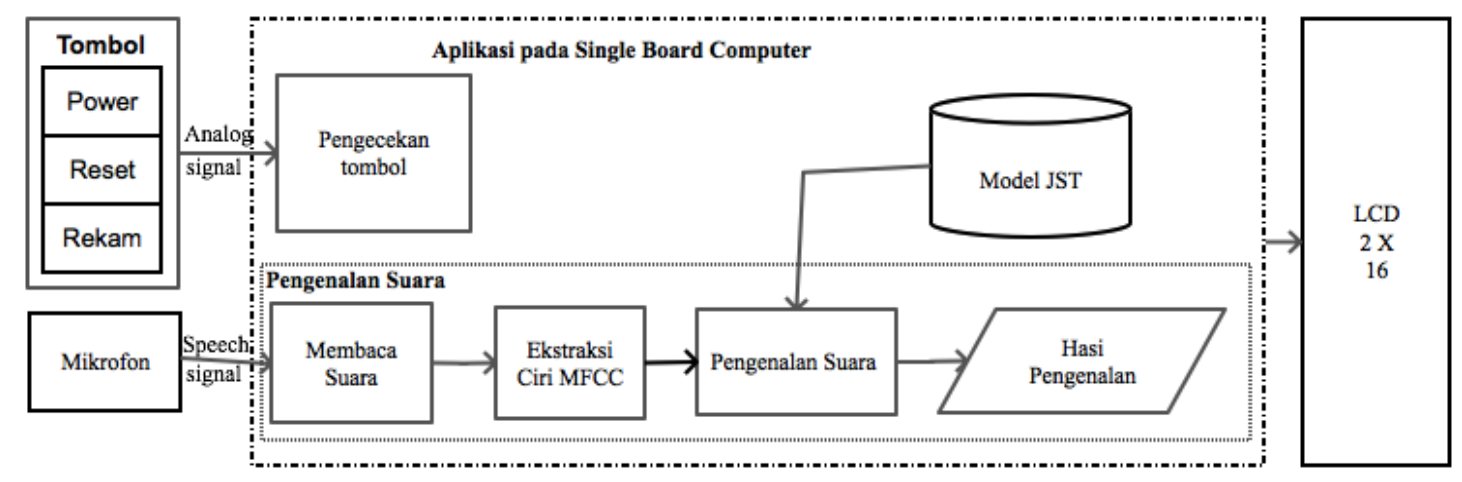

Gambar 1 Bagan alir sistem identifikasi kata ucapan tuna wicara

IJEIS Vol. 9, No. 2, October 2019: 131 - 140 


\subsection{Data Penelitian}

Metode JST backpropagation membutuhkan data masukan, dalam hal ini menggunakan fitur suara yang telah diekstraksi menggunakan metode MFCC. Adapun data yang digunakan pada penelitian ini ditunjukkan pada Tabel 1 dan 2.

Tabel 1 Data untuk pelatihan

\begin{tabular}{|r|l|r|}
\hline No. & Kata & Jumlah Suara \\
\hline 1 & Harga & 150 \\
\hline 2 & Kerja & 150 \\
\hline 3 & Makan & 150 \\
\hline 4 & Lapar & 150 \\
\hline 5 & Kamar & 150 \\
\hline
\end{tabular}

Tabel 2 Data untuk pengujian

\begin{tabular}{|r|l|r|}
\hline No. & Kata & Jumlah Suara \\
\hline 1 & Harga & 25 \\
\hline 2 & Kerja & 25 \\
\hline 3 & Makan & 25 \\
\hline 4 & Lapar & 25 \\
\hline 5 & Kamar & 25 \\
\hline
\end{tabular}

\subsection{Perancangan Sistem dan Alat Identifikasi Kata}

Sebagaimana ditunjukkan pada Gambar 1, yang berfungsi sebagai masukan adalah sensor suara atau mikrofon, Single Board Computer (SBC) sebagai pemproses dan LCD sebagai luaran.

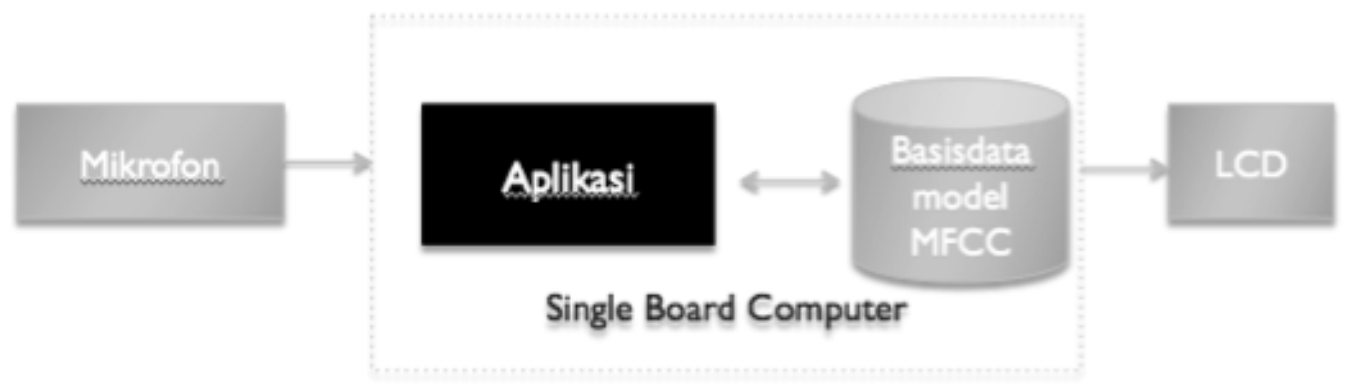

Gambar 2 Diagram blok sistem dan alat identifikasi kata

\subsubsection{Mikrofon}

Mikrofon akan menangkap suara tunawicara sebagai masukan untuk sistem, lalu suara tersebut akan diproses oleh sistem yang sudah tertanam pada SBC.

\subsubsection{Single Board Computer (SBC)}

SBC digunakan untuk memproses sinyal suara, termasuk proses pengenalan pola, sehingga akan diketahui arti dari sinyal suara tersebut, hasil tersebut akan ditampilkan pada LCD. Aplikasi yang tertanam pada SBC bertugas untuk membaca masukan dari mikrofon, melakukan pra-pemrosesan, ekstraksi fitur, pengenalan pola (perbandingan fitur masukan ke basisdata model MFCC) dan menampilkan arti suara melalui LCD. Diagram blok aplikasi yang dijalankan SBC ditunjukkan pada Gambar 3. 


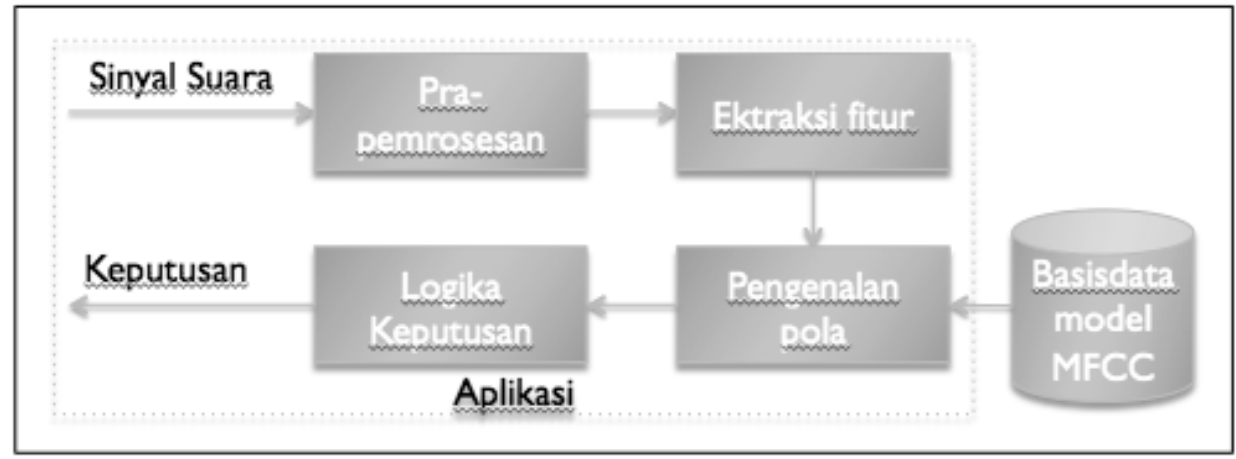

Gambar 3 Diagram blok aplikasi

Alur proses yang dijalankan pada SBC meliputi:

a. Pra-pemrosesan

Sinyal yang ditangkap oleh mikrofon akan ditapis menggunakan penapis lowpass untuk menghilangkan atau mereduksi derau atau noise, meningkatkan energi sinyal dan melakukan normalisasi dari sinyal mentah ke dalam sinyal berskala sama.

b. Ektraksi fitur

Setelah dilakukan pra-pemrosesan sinyal, proses selanjutnya adalah pencarian fitur menggunakan algoritma MFCC.

c. Pengenalan pola

Melakukan perbandingan pola dari pola masukan mikrofon dengan pola-pola yang tersimpan pada basisdata model MFCC.

d. Logika keputusan

Setelah pola dikenali, maka akan diperoleh arti kata dari suara yang ditangkap oleh mikrofon, arti kata akan ditampilkan di LCD.

\subsubsection{Basisdata model MFCC}

yaitu:

Basisdata ini menyimpan model fitur dari suara yang telah melewati berbagai proses,

1. Ekstraksi fitur

Ekstraksi fitur speech akan menggunakan MFCC yang nantinya akan menghasilkan vektor fitur MFCC. Fitur MFCC dihitung menggunakan parameter-parameter berikut:

- Pre-emphasis coefficients $=-0,95$

- Frame size $=256$ samples $(16 \mathrm{~ms})$

- Frame overlap $=85$ samples $(5,3 \mathrm{~ms})$

- Number of Triangular bandpass filters $=20$

- Number of MFCCs $=6$ dan 12

2. Klasifikasi fitur

Klasifikasi fitur akan menggunakan JST backpropagation (sebagaimana ditunjukkan pada Gambar 4) dengan multi-layer perceptron yang memiliki fase maju (forward) dan fase balik (back) dan fitur yang akan digunakan adalah MFCC. Adapun hasil pelatihan menggunakan JST yang terbaik dalam kasus ini adalah yang memiliki nilai epoch dan error terkecil. Fitur MFCC berupa vektor (bernilai bilangan asli) dari fitur sinyal yang dihasilkan dari proses frame blocking \& windowing, FFT, Mel Frequency wrapping, Log dan Discrete Cosine Transform (DCT). Konfigurasi yang digunakan JST sebagai berikut :

- Input layers $=6$ dan 12 nodes

- Hidden layers $=4$ nodes

IJEIS Vol. 9, No. 2, October 2019: 131 - 140 
- Output layers $=3$ nodes

- Hidden layer transfer function = Hyperbolic tangent

- Output layer transfer function = Linear

- Epoh = 0, MSE =1.

- Maksimum Epoh = 100.000,

- Target Error $=1$ e-010

- Learning Rate $=0,2$

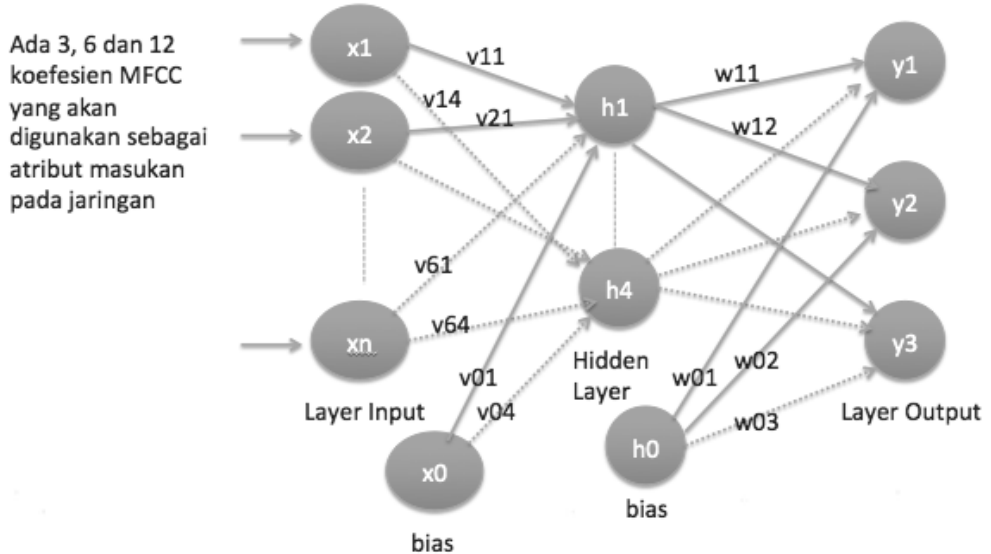

Gambar 4 Arsitektur pelatihan JST

Jumlah node masukan sama dengan jumlah koefisien yang diperoleh dari MFCC, jadi menggunakan 6 dan 12 node masukan.

3. Pelatihan dan Pengujian Fitur

Kegiatan pelatihan tergolong berat karena banyaknya proses yang dilakukan, oleh karena itu dilakukan menggunakan komputer dan perangkat lunak Matlab. Diagram blok pelatihan dapat ditunjukkan pada Gambar 5.

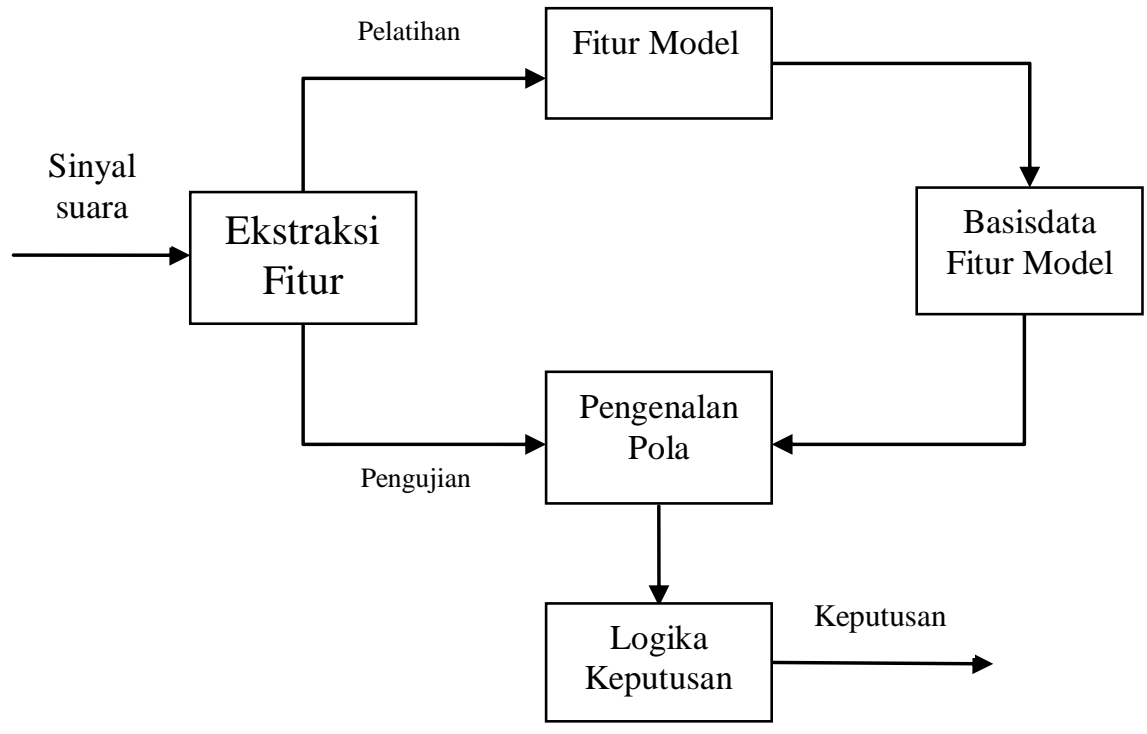

Gambar 5 Blok diagram klasifikasi fitur 


\subsubsection{LCD} sistem.

LCD sebagai sarana luaran, menampilkan arti dari kata yang sudah ditentukan oleh

\subsection{Perancangan Sistem}

Mikrofon digunakan sebagai masukan untuk sistem, sebagaimana ditunjukkan pada Gambar 6. Mikrofon, sebagai sensor suara, menghasilkan sinyal analog yang kemudian dilewatkan ADC (Analog to Digital Converter) agar diperoleh sinyal digital terkait. Sinyal digital tersebut menjadi masukan untuk SBC yang sudah dilengkapi dengan modul JST.

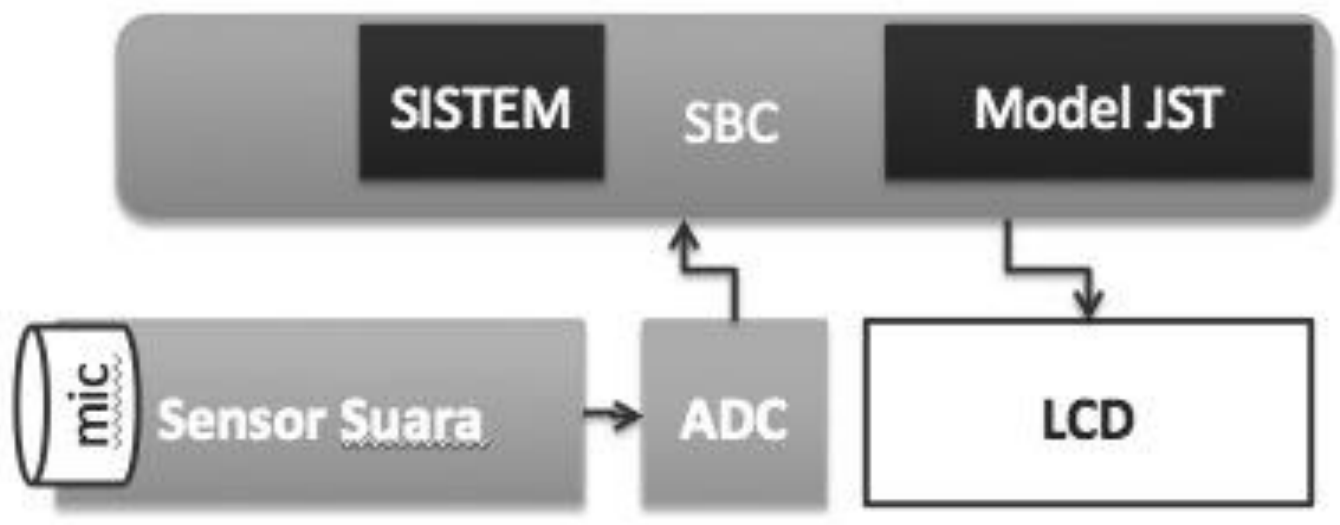

Gambar 6 Blok diagram alat

Setelah alat dirakit (sebagaimana ditunjukkan pada Gambar 10) dan ditanamkan program terkait kedalamnya, selanjutnya dilakukan pengujian. Gambar 7 menunjukkan saat alat dihidupkan untuk pertama kali, yaitu melakukan proses inisialisasi, kemudian beberapa saat alat akan siap untuk menerima data suara yang akan dikenali (ditunjukkan pada Gambar 8). Kata yang diucapkan, akan ditangkap oleh sensor, lalu akan di proses oleh sistem yang sudah ditanam di SBC, lalu akan menampilkan hasil, sebagaimana ditunjukkan pada Gambar 9.

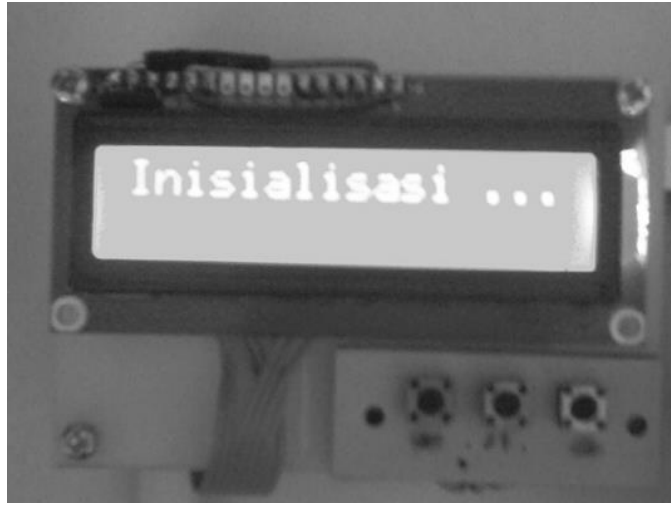

Gambar 7 Proses inisialisasi

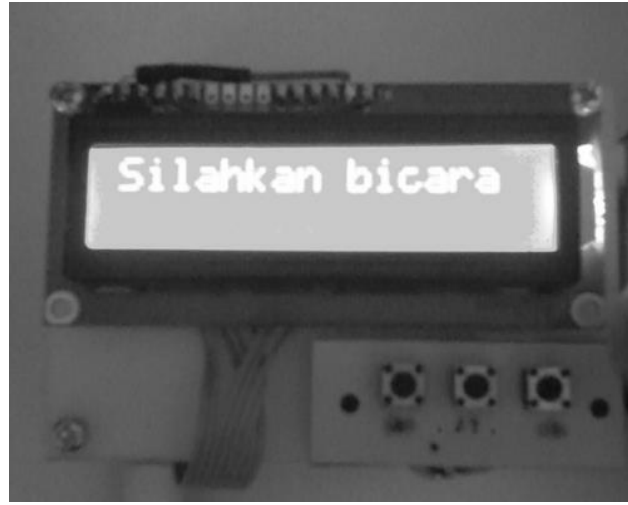

Gambar 8 Alat siap untuk menerima masukan kata 


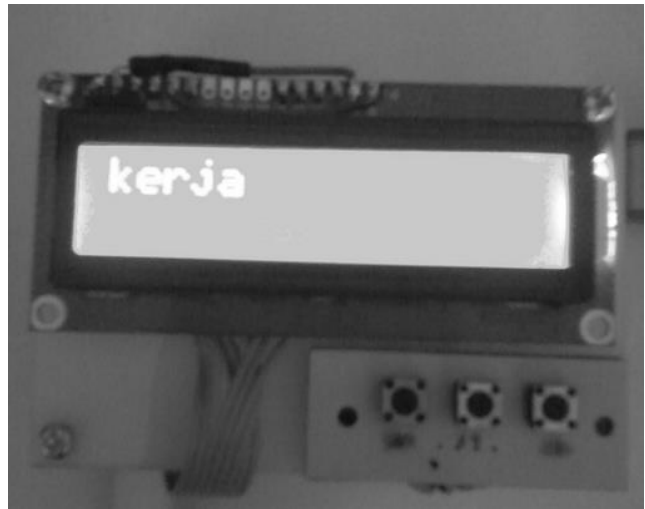

Gambar 9 Hasil diteksi suara pada alat

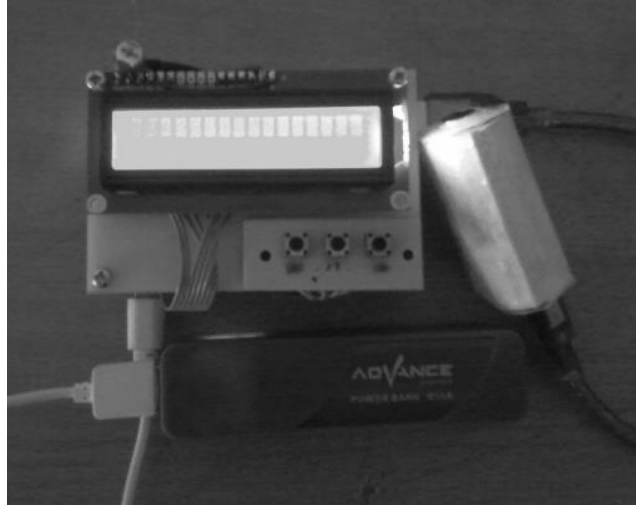

Gambar 10 Tampilan alat yang sudah dirakit

\section{HASIL DAN PEMBAHASAN}

\subsection{Hasil Penelitian}

Hasil pelatihan dan pengujian JST Backpropagation menggunakan beberapa kombinasi learning rate, maksimal epoch dan nilai toleransi error ditunjukan pada Tabel 3.

Tabel 3 Hasil akurasi pelatihan dari masing-masing penutur

a. Learning rate $=0,2$, maksimal epoch $=100.000$, toleransi error $=0,05$

\begin{tabular}{|c|c|c|}
\hline Data Penutur & \multicolumn{2}{|c|}{ Koefisien } \\
\hline & $\mathbf{6}$ & $\mathbf{1 2}$ \\
\hline 1 & $40 \%$ & $50 \%$ \\
\hline 2 & $60 \%$ & $60 \%$ \\
\hline 3 & $60 \%$ & $50 \%$ \\
\hline 4 & $60 \%$ & $50 \%$ \\
\hline 5 & $50 \%$ & $50 \%$ \\
\hline Rata-rata & $54 \%$ & $52 \%$ \\
\hline
\end{tabular}

b. Learning rate $=0,03$, maksimal epoch $=100.000$, toleransi error $=0,00001$

\begin{tabular}{|c|c|c|}
\hline Data Penutur & \multicolumn{2}{|c|}{ Koefisien } \\
\hline 1 & 6 & 12 \\
\hline 2 & $50 \%$ & $50 \%$ \\
\hline 3 & $50 \%$ & $60 \%$ \\
\hline 4 & $60 \%$ & $50 \%$ \\
\hline 5 & $60 \%$ & $50 \%$ \\
\hline Rata-rata & $60 \%$ & $50 \%$ \\
\hline
\end{tabular}

c. Learning rate $=0,03$, , maksimal epoch $=1.000 .000$, toleransi error $=0,00001$

\begin{tabular}{|c|c|c|}
\hline Data Penutur & \multicolumn{2}{|c|}{ Koefisien } \\
\hline & 6 & 12 \\
\hline 1 & $60 \%$ & $50 \%$ \\
\hline 2 & $50 \%$ & $60 \%$ \\
\hline 3 & $70 \%$ & $50 \%$ \\
\hline 4 & $60 \%$ & $50 \%$ \\
\hline 5 & $50 \%$ & $50 \%$ \\
\hline Rata-rata & $58 \%$ & $52 \%$ \\
\hline
\end{tabular}




\subsection{Pelatihan dan Pengujian Sistem}

Tabel 3a, Tabel 3b, dan Tabel 3c menunjukan bahwa masukan JST Backpropagation menggunakan 6 koefisien memiliki rerata akurasi lebih baik, yaitu 54\%, 56\% dan $58 \%$. Berdasarkan rerata akurasi koefisien 6 dan 12 (yang diperoleh dari rata-rata akurasi semua penutur) dapat disimpulkan bahwa hasil pada Tabel 3c mendapat hasil yang paling tinggi, menggunakan masukan 6 koefisien MFCC dan dilatih menggunakan JST dengan parameter learning rate $=0.03$, maksimal epoch $=1.000 .000$ dan toleransi error $=0.00001$.

Tabel 4 Hasil akurasi pengujian dari masing-masing penutur

\begin{tabular}{|c|r|r|}
\hline Data penutur & \multicolumn{2}{|c|}{ Koefisien } \\
\hline & $\mathbf{6}$ & \multicolumn{1}{|c|}{$\mathbf{1 2}$} \\
\hline $\mathbf{1}$ & $54 \%$ & $50 \%$ \\
\hline $\mathbf{2}$ & $50 \%$ & $50 \%$ \\
\hline $\mathbf{3}$ & $60 \%$ & $50 \%$ \\
\hline $\mathbf{4}$ & $50 \%$ & $34 \%$ \\
\hline $\mathbf{5}$ & $54 \%$ & $50 \%$ \\
\hline \multicolumn{2}{|c|}{ Akurasi Pengujian (\%) } \\
\hline \multicolumn{2}{|c}{} \\
\hline
\end{tabular}

Proses pengujian mendapatkan hasil yang berbeda-beda, sebagaimana ditunjukan pada Tabel 4. Rata-rata akurasi tertinggi untuk semua penutur sebesar 54\% ketika menggunakan MFCC dengan 6 koefisien.

\subsection{Pengujian Alat Identifikasi Kata Ucapan Tunawicara}

Selain melakukan pengujian fungsional, dilakukan juga pengujian secara realtime menggunakan alat. Hasil akurasi, presisi dan sensitivitas dari masing-masing penutur ditunjukan pada Tabel 5. Pengujian menggunakan gabungan dari semua data penutur mendapatkan akurasi sebesar $40 \%$ menggunakan 6 koefisien MFCC. Tabel 5 juga menunjukan akurasi tertinggi ketika menggunakan data penutur ke 3 yaitu $60 \%$, pengujian menggunakan data penutur 1, 2, 4 dan 5 mendapatkan hasil yang sama yaitu $50 \%$. Sedangkan untuk presisi dan sensitivity dari pengujian per penutur, memiliki persentase yang sama, yaitu $40 \%$ untuk penutur 1, 2, 3 dan 5 serta $50 \%$ untuk penutur 3 .

Tabel 5 Hasil akurasi alat dari masing-masing penutur

\begin{tabular}{|c|r|r|r|}
\hline Penutur & Akurasi & \multicolumn{1}{c|}{ Presisi } & \multicolumn{1}{c|}{ Sensitivity } \\
\hline 1 & $50 \%$ & $40 \%$ & $40 \%$ \\
\hline 2 & $50 \%$ & $40 \%$ & $40 \%$ \\
\hline 3 & $60 \%$ & $50 \%$ & $50 \%$ \\
\hline 4 & $50 \%$ & $40 \%$ & $40 \%$ \\
\hline 5 & $50 \%$ & $40 \%$ & $40 \%$ \\
\hline
\end{tabular}

\section{KESIMPULAN}

Telah dibuat sebuah sistem (alat) yang mampu mengidentifikasi kata ucapan seorang tunawicara menggunakan metode MFCC dan JST Backpropagation. Akurasi alat mencapai $50 \%$ pada pengujian menggunakan data penutur 1, 2,4 dan 5 serta $60 \%$ ketika menggunakan data penutur 3. Presisi dan sensitivitas alat identifikasi mendapatkan persentase yang sama, 
yaitu $40 \%$ untuk penutur 1, 2, 4 dan 5 serta $50 \%$ untuk penutur 3 . Alat memiliki sensitivitas $40 \%$, presisi $40 \%$, akurasi $50 \%$ untuk pengujian menggunakan semua data penutur.

\section{SARAN}

Perlu dilakukan penambahan fitur yang digunakan sebagai masukan JST dan memilih sensor suara yang lebih baik lagi, yang mampu bertahan terhadap noise.

\section{DAFTAR PUSTAKA}

[1] Hikmat, R. H., "Booklet Kementerian Sosial, Badan Pendidikan dan Penelitian Kesejahteraan Sosial Pusat Data dan Informasi Kesejahteraan Sosial Jakarta," halaman 54. 2012 [Online].Available:http://perpustakaan.bappenas.go.id/lontar/file?file=digital/143165\%5B_Konten_\%5D-Konten\%20D72.pdf [Accessed: 13-Juli- 2019].

[2] Chandra, E., Manikandan, K., dan Sivasankar, M., "A Proportional Study On Feature Extraction Method In Automatic Speech Recognition System," International Journal Of Innovative Research In Electrical, Electronics, Instrumentation And Control Engineering Vol. 2, Issue 1 , January 2014, ISSN(Online) : 2321 - 2004, ISSN(Print) : 2321 - 5526. [Online].Available:https://ijireeice.com/wp-

content/uploads/2013/03/IJIREEICE5C_s_siva_A_proportional.pdf [Accessed: 13-Juli2019].

[3] Srinivasan, V., Ramalingam, V., dan Arulmozhi, P., "Artificial Neural Network Based Pathological Voice Classification Using MFCC Features," International Journal Of Science, Environment And Technology, Vol. 3, No 1, 2014, 291 - 302, ISSN 2278-3687. [Online].

Available:https://pdfs.semanticscholar.org/241b/313fd5758095d74abe8da7b8aa22e2348075 .pdf [Accessed: 13-Juli- 2019].

[4] Chauhan, H.B. and Tanawala, B.A., "Comparative study of MFCC and LPC algorithms for Gujrati isolated word recognition," International Journal of Innovative Research in Computer and Communication Engineering, 3(2), pp.822-826. 2015 [Online]. Available: https://pdfs.semanticscholar.org/7c26/a9a579e14a1034eee909a2f34f12f5e44ae3.pdf [Accessed: 13-Juli- 2019].

[5] Desai N. , Dhameliya Kinnal., dan Desai Vijayendra., "Feature Extraction and Classification Techniques for Speech Recognition: A Review," International Journal of Emerging Technology and Advanced Engineering, Volume 3, Issue 12, December 2013, ISSN 2250-2459, ISO 9001:2008 Certified Journal. 2013 [Online]. Available:https://ijireeice.com/wp-

content/uploads/2013/03/IJIREEICE5C_s_siva_A_proportional.pdf [Accessed: 13-Juli2019].

[6] Wang, Y. and Lawlor, B., "Speaker recognition based on MFCC and BP neural networks," In 2017 28th Irish Signals and Systems Conference (ISSC) (pp. 1-4). IEEE. 2017 [Online]. Available: https://ieeexplore.ieee.org/abstract/document/7983644 [Accessed: 13-Juli- 2019].

[7] Asda, T.M.H., Gunawan, T.S., Kartiwi, M. and Mansor, H., "Development of Quran reciter identification system using MFCC and neural network," Indonesian Journal of Electrical Engineering and Computer Science, 1(1), pp.168-175. 2016 [Online]. Available: 
https://www.researchgate.net/profile/Teddy_Gunawan/publication/299433726_Developmen t_of_Quran_Reciter_Identification_System_Using_MFCC_and_Neural_Network/links/591 9b70b0f7e9b1db6527de1/Development-of-Quran-Reciter-Identification-System-UsingMFCC-and-Neural-Network.pdf [Accessed: 13-Juli- 2019].

[8] Srivastava, N., "Speech recognition using artificial neural network," International Journal of Engineering Science and Innovative Technology (IJESIT), 3(3), pp.406-408. 2014 [Online].

Available:https://pdfs.semanticscholar.org/5f0c/0fa960bb59294c8351a315824d3582735ab5 .pdf [Accessed: 13-Juli- 2019].

[9] Sivan, S. dan Gopakumar, C., "An MFCC Based Speaker Recognition using ANN with Improved Recognition Rate," International Journal of Emerging Technologies in Computational and Applied Sciences (IJETCAS). 2014 [Online]. Available:http://iasir.net/IJETCASpapers/IJETCAS14-426.pdf [Accessed: 13-Juli- 2019].

[10] Sharma S., Shukla A., Mishra Pankaj, "Speech and Language Recognition using MFCC and DELTA-MFCC," International Journal of Engineering Trends and Technology (IJETT) - Volume 12 Number 9 - Jun 2014. [Online]. Available:http://ijettjournal.org/archive/ijettv12p286[Accessed: 13-Juli- 2019]. 